\title{
Predicting the minimal inhibitory concentration of fluoroquinolones for Escherichia coli using an accumulation model
}

\author{
Wen Zhang, Chenyin Wang and Kin Y. Tam* \\ Faculty of Health Sciences, University of Macau, Macau, China
}

\begin{abstract}
The objective of this study is to evaluate whether the accumulation model developed by Zarfl et al. (2008) could be used to predict the minimal inhibitory concentration (MIC) of a group of antibacterial fluoroquinolones (FQs) for Escherichia coli (E. coli). Our model, which is based on the "Fick-Nernst-Planck" equation and the permeability of the neutral and charged species as well as the physicochemical parameters of the $\mathrm{FQs}$, could predict $1 / \mathrm{MIC}_{90}$ using a linear function. It is envisaged that in the drug development projects of new FQs, the accumulation model described in this study could be utilized as an effective tool to enable early assessment of MIC value using physiochemical parameters.
\end{abstract}

Keywords: Fluoroquinolones, minimal inhibitory concentration, Escherichia coli, physicochemical parameters

\section{Introduction}

Fluoroquinolones (FQs) are broad spectrum antimicrobial agents which are active against many Gram-positive and Gram-negative bacteria [1]. These molecules contain one acid and one base with the protonation macroconstants close to each other. Figure 1 shows four different $\mathrm{pH}$-dependent protonation states of the molecule, namely cation $\left(\mathrm{H}_{2} \mathrm{X}^{+}\right)$, zwitterions $\left(\mathrm{HX}^{ \pm}\right)$, neutral species $\left(\mathrm{HX}^{0}\right)$ and anion $\left(\mathrm{X}^{-}\right)$. The mole fractions of the zwitterionic and neutral species reach the maximal amount at the isoelectric point while their ratio is invariable and $\mathrm{pH}$-independent. It has been reported that the antibacterial potency of FQ are predominantly driven by the concentration of the drug in proximity to the intercellular targets $[2,3]$.

There is a great demand for new antibiotics to address emerging bacterial infections $[3,4]$. In the development of antibiotics, one of the frequently used approaches is to enhance the potency by modifying the existing antimicrobial agents, such as FQs [5]. The microbiological potency of the compounds would be assessed by using the minimum inhibitory concentration (MIC) for the pathogen. MIC is defined as the lowest concentration of an antimicrobial agent that will inhibit the visible

\footnotetext{
${ }^{*}$ Corresponding author: Kin Y. Tam, Faculty of Health Sciences, University of Macau, Macau, China. Tel.: +8538822 4988; Fax: +853 8822 2314; E-mail: kintam@umac.mo.
} 


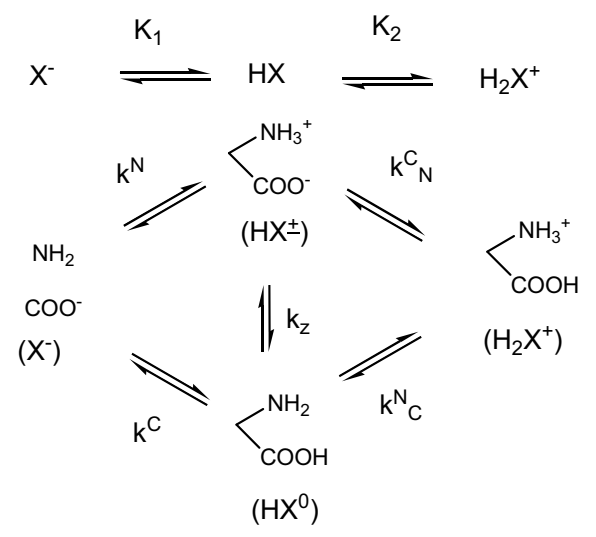

Fig. 1. Ionization scheme of a diprotic amphoteric molecule.

growth of a microorganism at an endpoint of overnight incubation [6]. In practice, it usually refers to the lowest concentration that inhibits $50 \%\left(\mathrm{MIC}_{50}\right)$ or $90 \%\left(\mathrm{MIC}_{90}\right)$ of bacterial colonies or isolates and can indicate shifts in the susceptibility of bacterial populations to antimicrobial agents. Therefore, the mechanistic rationalization of the factors driving the MIC values, and the ability to predict these values reliably would be of considerable interest in the course of developing antimicrobial agents.

Trapp and others [7-10] have modeled the flux of neutral and ionic compounds into cells by employing a dynamic cell model based on the "Fick-Nernst-Planck" formula. Interestingly, Zarfl et al. [11] have adopted this model to simulate the accumulation of antibacterial sulfonamides in Escherichia coli (E. coli) based on various assumptions on the permeability of the neutral and ionized species. In this work, we seek to extend the accumulation model to study the MIC values of a set of FQs for E. coli. In particular, the neutral, the zwitterionic and the ionized species of the FQs will be considered independently with their permeability values estimated using the physicochemical parameters of the compounds. As far as we are aware, the accumulation model has not been applied to study FQs.

\section{Materials and methods}

\subsection{Drugs and chemicals}

Moxifloxacin was supplied by AstraZeneca (Alderley Park, UK). Norfloxacin, lomefloxacin, ofloxacin, pefloxacin, sparfloxacin, gatifloxacin and other chemicals were supplied by Sigma-Aldrich (St. Louis, US).

\subsection{Determination of protonation macroconstants}

The protonation macroconstants were determined by means of $\mathrm{pH}$-metric titrations $\left(\mathrm{GLpK}_{\mathrm{a}}\right.$ instrument, Sirius, Forest Row, UK). 


\subsection{Determination of protonation microconstants}

The protonation microconstants were determined by means of UV-titrations. As shown in Figure 1, the microconstant, $\mathrm{k}^{\mathrm{C}}$, is influenced by the protonation state of the carboxylate group, which can be detected by selective spectrophotometric monitoring of the spectral region of $320-350 \mathrm{~nm}$. The $\log \mathrm{k}^{\mathrm{C}}$ value was derived by using Eqs. (1) and (2):

$$
\begin{aligned}
& \alpha_{\mathrm{COO}^{-(\mathrm{PH})}}=\frac{\mathrm{A}_{\left(\mathrm{COO}^{\prime}\right)}-\mathrm{A}_{(\mathrm{PH})}}{\mathrm{A}_{\left(\mathrm{COO}^{\prime}\right)}-\mathrm{A}_{(\mathrm{COOH})}} \\
& \mathrm{k}^{\mathrm{C}}=\frac{\alpha_{\mathrm{COO}^{-}(\mathrm{PH})}\left(1+\mathrm{K}_{1}\left[\mathrm{H}^{+}\right]+\mathrm{K}_{1} \mathrm{~K}_{2}\left[\mathrm{H}^{+}\right]^{2}\right)-\mathrm{K}_{1} \mathrm{~K}_{2}\left[\mathrm{H}^{+}\right]^{2}}{\left[\mathrm{H}^{+}\right]}
\end{aligned}
$$

where $\mathrm{A}_{(\mathrm{COO})}$ and $\mathrm{A}_{(\mathrm{COOH})}$ represents, respectively, the experimental absorbance values at a $\mathrm{pH}$ in which the acid group is fully deprotonated and fully protonated. The symbol $\alpha_{\mathrm{COO}}{ }^{-}(\mathrm{pH})$ represents the degree of protonation at the $\mathrm{pH}$ in which the absorbance value is denoted as $\mathrm{A}_{(\mathrm{pH})}$. With the $\log \mathrm{k}^{\mathrm{C}}$ value determined (see Eq. (2)), the other microconstants can be derived by using Eqs. (3) and (4):

$$
\begin{aligned}
& \mathrm{K}_{1}=\mathrm{k}^{\mathrm{C}}+\mathrm{k}^{\mathrm{N}} \\
& \mathrm{K}_{1} \mathrm{~K}_{2}=\mathrm{k}^{\mathrm{C}} \mathrm{k}^{\mathrm{N}}{ }_{\mathrm{C}}=\mathrm{k}^{\mathrm{N}} \mathrm{k}^{\mathrm{C}}{ }_{\mathrm{N}}
\end{aligned}
$$

In addition, the ratio of the concentration of zwitterions species to that of the neutral species, which is defined as the tautomer ratio $\left(\mathrm{k}_{\mathrm{z}}\right)$, could be calculated by Eq. (5):

$$
\mathrm{k}_{\mathrm{z}}=\frac{\mathrm{k}^{\mathrm{N}}}{\mathrm{k}^{\mathrm{C}}}=\frac{\mathrm{k}^{\mathrm{N}} \mathrm{C}}{\mathrm{k}^{\mathrm{C}} \mathrm{N}}
$$

\subsection{Measurement of partition coefficients}

The $\mathrm{n}$-octanol/water partition coefficient at the isoelectric point $\left(\log \mathrm{D}^{\mathrm{iepH}}\right)$ was determined by using the shake-flask technique. The $\log \mathrm{D}^{\mathrm{iepH}}$ value was calculated as follows:

$$
\log \mathrm{D}^{\mathrm{iepH}}=\log \left[\frac{\mathrm{A}_{0}-\mathrm{A}_{1}}{\mathrm{~A}_{1}}\left(\frac{\mathrm{V}_{\text {aq }}}{\mathrm{V}_{\text {oct }}}\right)\right]
$$

where $A_{0}$ and $A_{1}$ denote the $\mathrm{UV} /$ visible absorbance value, before and after partition, at the maximal absorption of the chemical in the aqueous environment, respectively. $\mathrm{V}_{\mathrm{aq}} / \mathrm{V}_{\text {oct }}$ represents the ratio of aqueous volume to n-octanol volume. 


\subsection{Accumulation model}

The uptake rate $\left(k_{\mathrm{u}}\right)$ of the drug across the bacterial cell wall and the release rate $\left(\mathrm{k}_{\mathrm{r}}\right)$ of the drug to the environment are taken into consideration in the accumulation model developed by Zarfl et al. [11]. At steady state in which the rate of change of drug concentration (C) within the bacterial cell is zero, the accumulation factor (AF) can be defined as follows:

$$
\begin{aligned}
& \mathrm{AF}=\frac{\mathrm{C}_{\mathrm{cell}}}{\mathrm{C}_{\mathrm{env}}}=\frac{\mathrm{k}_{\mathrm{u}}}{\mathrm{k}_{\mathrm{r}}} \\
& \mathrm{k}_{\mathrm{r}}=\mathrm{P}_{0} \gamma_{0} \mathrm{f}(0)_{\text {cell }}+\mathrm{P}_{ \pm} \gamma_{0} \mathrm{f}( \pm)_{\text {cell }}+\mathrm{P}_{+} \frac{\mathrm{N}_{+}}{\mathrm{e}^{\mathrm{N}_{+}}-1} \gamma_{+} \mathrm{f}(+)_{\text {cell }} \mathrm{e}^{\mathrm{N}_{+}}+\mathrm{P}_{-} \frac{\mathrm{N}-}{\mathrm{e}^{\mathrm{N}_{-}}-1} \gamma_{-} \mathrm{f}(-)_{\text {cell }} \mathrm{e}^{\mathrm{N}_{-}} \\
& \mathrm{k}_{\mathrm{u}}=\mathrm{P}_{0} \mathrm{f}(0)_{\text {env }}+\mathrm{P}_{ \pm} \mathrm{f}( \pm)_{\text {env }}+\mathrm{P}_{+} \frac{\mathrm{N}_{+}}{\mathrm{e}^{\mathrm{N}_{+}}-1} \mathrm{f}(+)_{\text {env }}+\mathrm{P}_{-} \frac{\mathrm{N}_{-}}{\mathrm{e}^{\mathrm{N} .}-1} \mathrm{f}(-)_{\text {env }}
\end{aligned}
$$

where the subscripts cell and env denote, respectively, the cell and environment $\mathrm{pH}$. The intracellular $\mathrm{pH}$ is set at 7.6 for bacterial cytoplasm [12], while the environment $\mathrm{pH}$ is arbitrarily defined at 6 . The symbol $\gamma$ represents the activity coefficient of the respective species in the cell $\left(\gamma_{0}=1.23 ; \gamma_{-}=\gamma_{+}=\right.$ 0.74 , assuming the ionic strength of the cytoplasm of $E$. coli is about $0.3 \mathrm{M}$ ). $\mathrm{N}$ is defined as $\mathrm{z} \times \mathrm{E} \times \mathrm{F} /(\mathrm{R} \times \mathrm{T})$, with $\mathrm{z}$ the electric charge ( +1 for cations, -1 for anions), $\mathrm{F}$ the Faraday constant $\left(96484.56 \mathrm{C} \mathrm{mol}^{-1}\right), \mathrm{R}$ the universal gas constant $\left(8.314 \mathrm{~J} \mathrm{~mol}^{-1} \mathrm{~K}^{-1}\right)$, $\mathrm{T}$ the absolute temperature $(\mathrm{K})$ and $\mathrm{E}$ the membrane potential for $E$. coli which is about $-0.11 \mathrm{~V}[12]\left(\mathrm{N}_{+}=-4.28 ; \mathrm{N}_{-}=4.28\right)$.

The symbols $\mathrm{f}$ and $\mathrm{P}$ represent, respectively, the fraction of the species with respect to the corresponding charge types and the permeability of these species across the bacterial cell wall. The fraction of the species as a function of $\mathrm{pH}$ can be calculated using the protonation microconstants of the corresponding FQs [13]. The permeability of the neutral species across the bacterial cell wall is estimated as follows [11]:

$$
\log \mathrm{P}_{0} \approx \log \mathrm{D}^{\mathrm{iepH}}-6.30
$$

The permeability of the zwitterionic and the ionic species are calculated as follows:

$$
\log \mathrm{P}_{ \pm}=\log \mathrm{P}_{0}-\delta_{\mathrm{ZW}} \text { and } \log \mathrm{P}_{+}=\log \mathrm{P}_{-}=\log \mathrm{P}_{0}-\delta_{\text {ion }}
$$

where $\delta_{\mathrm{ZW}}$ and $\delta_{\text {ion }}$ are treated as adjustable parameters in our analysis.

\section{Results and discussion}

\subsection{Physicochemical parameters of fluoroquinolones}

Table 1 depicts the physical properties of the FQs studied in this paper, including $\log \mathrm{K}, \log \mathrm{k}$ and $\log \mathrm{D}^{\mathrm{iepH}}$. It shows that the $\mathrm{k}_{\mathrm{z}}$ ranges from 1.8 to 15.9 , which indicated the preference of zwitterion in- 
Table 1

Physical properties and antibacterial potency of the fluoroquinolones

\begin{tabular}{lllllllllll}
\hline Compound & $\log \mathrm{K}_{1}$ & $\log \mathrm{K}_{2}$ & $\mathrm{pH}_{\mathrm{IEP}}$ & $\log \mathrm{k}^{\mathrm{C}}$ & $\log \mathrm{k}_{\mathrm{N}}^{\mathrm{C}}$ & $\log \mathrm{k}^{\mathrm{N}}$ & $\log \mathrm{k}_{\mathrm{C}}^{\mathrm{N}}$ & $\mathrm{k}_{\mathrm{z}}$ & $\log ^{\mathrm{iepH}}$ & $\begin{array}{l}\mathrm{MIC} \mathrm{C}_{90} \\
(\mu \mathrm{g} / \mathrm{mL} \\
E . \text { coli }\end{array}$ \\
\hline Norfloxacin & $\begin{array}{l}8.52 \pm \\
0.01^{\mathrm{a}}\end{array}$ & $\begin{array}{l}6.29 \pm \\
0.01\end{array}$ & 7.4 & $\begin{array}{l}7.94 \pm \\
0.09\end{array}$ & 6.43 & 8.38 & 6.87 & 2.75 & -1.07 & $0.12^{\mathrm{b}}[14,15]$ \\
\hline Lomefloxacin & $\begin{array}{l}8.93 \pm \\
0.01\end{array}$ & $\begin{array}{l}5.83 \pm \\
0.01\end{array}$ & 7.4 & $\begin{array}{l}8.32 \pm \\
0.11\end{array}$ & 5.96 & 8.80 & 6.44 & 3.02 & -1.13 & $0.50[16]$ \\
\hline Ofloxacin & $\begin{array}{l}8.14 \pm \\
0.01\end{array}$ & $\begin{array}{l}6.03 \pm \\
0.01\end{array}$ & 7.1 & $\begin{array}{l}7.18 \pm \\
0.13\end{array}$ & 6.08 & 8.09 & 6.99 & 8.13 & -0.44 & $0.12[14]$ \\
\hline Pefloxacin & $\begin{array}{l}7.51 \pm \\
0.01\end{array}$ & $\begin{array}{l}6.26 \pm \\
0.01\end{array}$ & 6.9 & $\begin{array}{l}6.70 \pm \\
0.14\end{array}$ & 6.35 & 7.42 & 7.07 & 5.25 & 0.37 & $0.25[14]$ \\
\hline Sparfloxacin & $\begin{array}{l}8.97 \pm \\
0.01\end{array}$ & $\begin{array}{l}6.32 \pm \\
0.01\end{array}$ & 7.6 & $\begin{array}{l}8.52 \pm \\
0.09\end{array}$ & 6.52 & 8.77 & 6.77 & 1.78 & -0.09 & $0.13[16]$ \\
\hline Gatifloxacin & $\begin{array}{l}9.13 \pm \\
0.01\end{array}$ & $\begin{array}{l}5.97 \pm \\
0.01\end{array}$ & 7.6 & $\begin{array}{l}7.90 \pm \\
0.06\end{array}$ & 6.00 & 9.10 & 7.20 & 15.85 & -0.71 & $0.10[17]$ \\
\hline Moxifloxacin & $\begin{array}{l}9.32 \pm \\
0.01\end{array}$ & $\begin{array}{l}6.28 \pm \\
0.01\end{array}$ & 7.8 & $\begin{array}{l}8.23 \pm \\
0.11\end{array}$ & 6.32 & 9.28 & 7.37 & 11.22 & -0.26 & $0.06[18]$ \\
\hline
\end{tabular}

${ }^{\mathrm{a}}$ Uncertainty was calculated as the standard deviation of the results obtained from 3 different experiments.

${ }^{\mathrm{b}}$ Numbers in brackets referred to the source of the $\mathrm{MIC}_{90}$ data (see reference section).

aqueous phase. Thus, zwitterion of the FQ molecule is the dominating species across the physiological $\mathrm{pH}$ region, which is consistent with the low and moderate lipophilicity values $\left(\log \mathrm{D}^{\mathrm{iepH}}\right)$ as determined in this study.

\subsection{Modeling the MIC values}

Table 1 shows the $\mathrm{MIC}_{90}$ values of the studied FQs for E. coli, cited from several references. For gram-negative organisms (E. coli), the antibacterial agent must penetrate the outer lipid membrane and overcome the evasion of efflux pumps. It is generally considered that, in gram-negative bacteria, the porin proteins act as a principal entry pathway [19]. Polar species are expected to be able to enter the bacterial cell wall through these hydrophilic channels.

Assuming the bacterial cell metabolism does not affect the accumulation for the FQs significantly,

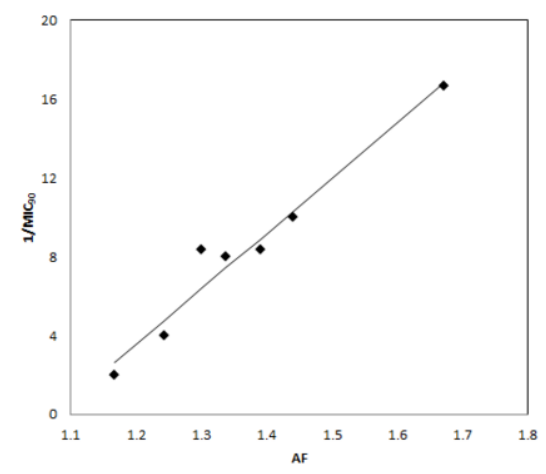

Fig. 2. Comparison of $1 / \mathrm{MIC}_{90}$ of the selected fluoroquinolones with the accumulation factor (AF). 
the antibiotic effects would be enhanced with the increase of drug accumulation in the cell. A regression analysis of $\mathrm{AF}$ (see Eq. (7)) against $1 / \mathrm{MIC}_{90}$ was carried out by treating $\delta_{\mathrm{ZW}}$ and $\delta_{\text {ion }}$ (see Eq. (11)) as adjustable parameters. As shown in Figure 2, a plot of $1 / \mathrm{MIC}_{90}$ as a function of AF exhibits a reasonably linear relationship, suggesting the generality of the model. It was found that the regression calculation converged to a global solution with $\delta_{\mathrm{ZW}}=0.38$ and $\delta_{\text {ion }}=0.57$, which are much smaller than that proposed by Zarfl et al. for the antibacterial sulfonamides [11]. Obviously, the smaller the $\delta$ value is, the closer the permeability of the ionic species to that of the neutral species would be (see Eq. (11)). This suggests that the zwitterionic, the cationic and the anionic species of FQs, play an important role in penetrating the bacterial cell wall to elicit the antibacterial effects in gram-negative organisms.

\subsection{Implications of our model}

Assuming the FQs process the same pharmacophore, it is very likely that the molecule binds to the target sites within the bacterial cell by means of a similar binding mode. Thus, the target affinity may be driven by lipophilicity. Early attempts by Taléns-Visconti et al. have demonstrated a bilinear relationship between 1/MIC and the distribution of constant $\mathrm{D}$ (at $\mathrm{pH}$ 7) on selected FQs [20]. However, little mechanistic insight can be obtained from this kind of empirical study. With the aid of the accumulation model, our treatment enables us to rationalize the contributions of the zwitterionic, the cationic and the anionic as well as the neutral species in the permeation of the bacterial cell wall.

We envisage that our model can be used to predict the MIC values in developing new FQs, well ahead of microbiological potency evaluations. These estimates could be helpful for the identification of the potent compounds for subsequent microbiological potency, pharmacokinetic and pharmacodynamics evaluations.

\section{Conclusion}

We have developed an accumulation model based on the physicochemical parameters of a set of FQs. The model was able to correlate the accumulation data with 1/MIC of FQs for E. coli. Our results suggest that the model could be beneficial to enable an early prediction of the MIC in the course of developing new FQs. The early MIC estimates would have great potential to help prioritizing the most prospective research chemicals and hence offer the optimal opportunity to distinguish new FQs with the anticipated MIC value. The feasibility of the accumulation models developed in this paper is well justified by the good agreement between the calculated data and literature.

\section{Acknowledgement}

We thank the financial support from the University of Macau (grant no.: SRG2013-00055-FHS).

\section{References}

[1] D.E. Nix and J.J. Schentag, The quinolones: An overview and comparative appraisal of their pharmacokinetics and pharmacodynamics, J. Clin. Pharmacol. 28 (1988), 169-178. 
[2] M.A. Mitscher, Bacterial topoisomerase inhibitors: Quinolone and pyridone antibacterial agents, Chem. Rev. 105 (2005), 559-592.

[3] L.L. Silver, Challenges of antibacterial discovery, Clin. Microbiol. Rev. 24 (2011), 71-109.

[4] D.M. Morens, G.K. Folkers and A.S. Fauci, The challenge of emerging and re-emerging infectious diseases, Nature 430 (2004), 242-249.

[5] K. Bush and M.J. Picci, New antimicrobial agents on the horizon, Biochem. Pharmacol. 82 (2011), 1528-1539.

[6] A. Dalhoff and F.J. Schmitz, In vitro antibacterial activity and pharmacodynamics of new quinolones, Eur. J. Clin. Microbiol. Infect. Dis. 22 (2003), 203-221.

[7] G.G. Briggs, R.L.O. Rigitano and R.H. Bromilow, Physico-chemical factors affecting uptake by roots and translocation to shoots of weak acids in barley, Pestic. Sci. 19 (1987), 101-112.

[8] D.A. Kleier, Phloem mobility of xenobiotics I, mathematical model unifying the weak acid and intermediate permeability theories, Plant. Physiol. 86 (1988), 803-810.

[9] S. Trapp, Modeling uptake into roots and subsequent translocation of neutral and ionisable organic compounds, Pest Manage Sci. 56 (2000), 767-778.

[10] S. Trapp, Plant uptake and transport models for neutral and ionic chemicals, Environ. Sci. Poll. Res. 11 (2004), 33-39.

[11] C. Zarfl, M. Matthies and J. Klasmeier, A mechanistical model for the uptake of sulfonamides by bacteria, Chemosphere 70 (2008), 753-760.

[12] D. Zilberstein, V. Agmon, S. Schuldiner and E. Padan, Escherichia coli intracellular $\mathrm{pH}$, membrane potential, and cell growth, J. Bacteriol. 158 (1984), 246-252.

[13] K. Takács-Novák and K.Y. Tam, Multiwavelength spectrophotometric determination of acid dissociation constants part V: Microconstants and tautomeric ratios of diprotic amphoteric drugs, J. Pharm. Biomed. Anal. 21 (2000), 1171-1182.

[14] J.S. Wolfson, H.C. Hooper, Fluoroquinolone antimicrobial agents, Clin. Microbiol. Rev. 2 (1989), $378-424$.

[15] D.M. Johnson, R.N. Jones, M.E. Erwin, In vitro antimicrobial activity of CP-99433 compared with other fluoroquinolones, Diagn. Microbiol. Infect. Dis. 17 (1993), 79-83.

[16] J.L. Oh, K.S. Paek, M.J. Ahn, M.Y. Kim, C.Y. Hong, I.C. Kim and J.H. Kwak, In vitro and in vivo evaluations of LB20304, a new fluoronaphthyridone, Antimicrob. Agents. Chemother. 40 (1996), 1564-1568.

[17] E. Wakabayashi and S. Mitsuhashi, In vitro antibacterial activity of AM-1155, a novel 6-fluoro 8-methoxy quinolone, Antimicrob. Agents. Chemother. 38 (1994), 594-601.

[18] R.J. Fass, In vitro activity of Bay 12-8039, a new 8-methoxy quinolone, Antimicrob. Agents. Chemother. 41 (1997), $1818-1824$

[19] H. Nikaido, Molecular basis of bacterial outer membrane permeability revisited, Microbiol. Mol. Biol. Rev. 67 (2003), 593-656.

[20] R. Taléns-Visconti, T.M. Garrigues, E. Cantón, J. Freixas, A. Martín-Villodre and J.M. Plá-Delfina, Activity-bioavailability balance in oral drug development for a selected group of 6-fluoroquinolones, J. Pharm. Sci. 91 (2002), 2452-2464. 